Balanço Bibliográfico

\title{
Compreensões sobre \\ a ascensão da criminalidade \\ e a reconstrução do Estado \\ iraquiano: nexos de competição \\ e complementaridade
}

(D) Priscila Villela ${ }^{1}$

Submetido em: 15/05/2020

https://orcid.org/0000-0003-2432-8900

Aceito em: 19/08/2020

(D) Rodrigo Augusto Duarte Amaral ${ }^{2}$

https://orcid.org/0000-0002-7245-5448

DOl: 10.17666/bib9701/2022

\section{Introdução}

Em março de 2003 os EUA invadiram o Iraque, removeram o partido Baath liderado por Saddam Hussein do poder e, a partir de então, iniciaram um processo de reconstrução das estruturas do Estado iraquiano. Notadamente, a ação intervencionista dos EUA ocorreu sem a devida aprovação do Conselho de Segurança das Nações Unidas (CSNU). Ainda que o órgão classificasse o Iraque como uma

\footnotetext{
'Priscila Villela é doutora em Relações Internacionais pelo PPGRI San Tiago Dantas (UNESP, UNICAMP, PUC-SP). Atua como professora de Relações Internacionais da PUC-SP e como pesquisadora do Núcleo de Estudos Transnacionais de Segurança (NETS). Pesquisa a dimensão transnacional da criminalidade e policiamento. E-mail: pvillela@pucsp.br.

"Rodrigo Augusto Duarte Amaral é professor do curso de Relações Internacionais da PUC-SP. Doutorando e Mestre em pelo PPGRI San Tiago Dantas (UNESP/ UNICAMP/PUCSP). Membro dos Grupos de Pesquisa - Grupo de Estudos sobre Conflitos Internacionais (GECI) e Núcleo de Estudos Transnacionais de Segurança (NETS) da PUCSP, e Grupo de Trabajo: Medio Oriente y norte de Africa da CLACSO. E-mail: radamaral@pucsp.br.

Publicado em: janeiro de 2022 | pp. 1-19
} 
ameaça (Resolução n ${ }^{\circ} 1441^{1}$ /2002), a ação intervencionista não foi reconhecida como legítima, razão pela qual o $\mathrm{CSNU}^{2}$ se manteve ausente. $O$ cenário se alterou em 22 de maio de 2003, quando o órgão reconheceu a ocupação liderada pelos norte-americanos no país, sob a prerrogativa de que o ambiente políticosocial crítico no Iraque exigia a necessidade de forças ocupantes agirem como "Autoridade Provisória".

A Resolução $n^{\circ} 1483$ aprovada no âmbito do CSNU responsabilizou os EUA a liderar uma coalizão internacional para reconstruir o Iraque, reconhecendo as autoridades, responsabilidades e obrigações específicas nos termos do direito internacional aplicável desses estados como poderes ocupantes. Formalmente, portanto, a proposta da Coalizão de Autoridade Provisória (CAP) liderada pelos EUA consistia em desenvolver um "novo Iraque". Para tanto, administrou o país por 14 meses, executando um plano de reconstrução que atingiu as bases mais profundas do país, como reformas estruturais políticas e econômicas.

Nesse processo, a agenda de combate à criminalidade ganhou destaque (CAP, 2003). A interpretação dominante dos tomadores de decisão foi de que os grupos criminosos ofereciam riscos ao estabelecimento do monopólio do uso da força estatal, ao mesmo tempo em que minavam a autoridade do ocupante, podendo ainda se tornar uma fonte de financiamento a grupos terroristas (ONU, 2003; CAP, 2004). Apesar dos esforços mobilizados para seu controle, um conjunto restrito de autores que se debruçaram sobre o tema notou haver um aumento na economia informal e na criminalidade após o processo de reconstrução (Looney, 2006; Williams, 2009; Herring; Rangwala, 2005).

Em função desse diagnóstico, estudiosos das Relações Internacionais buscaram compreender as especificidades da economia informal e da criminalidade no Iraque, bem como seus impactos sobre a reconstrução do país. A relação simbiótica entre crime e Estado, o impacto das reformas econômicas sobre a transnacionalização do crime e, por outro lado, as respostas inadequadas oferecidas pela CAP são alguns dos temas abordados por essa literatura.

Notamos, contudo, que o Iraque não foi um caso isolado. Em processos de reconstrução de Estado de diversas naturezas, seja no processo de ocupação do Iraque ou nas operações de paz da ONU, observa-se um mesmo problema: o de que a criminalidade se constitui como um obstáculo ao sucesso da reconstrução do Estado, ao mesmo tempo em é comum que seu crescimento avance ao longo desse processo.

Ainda que no Iraque não seja uma operação de paz (peacebuilding), conduzida sob os auspícios do CSNU e suas regras de engajamento, analistas afirmaram que

\footnotetext{
${ }^{1}$ Reconhecia o Iraque como potencial ameaça à paz e à segurança internacionais, visto que não respeitava as resoluções do Conselho que restringia a proliferação de armas de destruição maciça e de mísseis de longo alcance. Especificamente sobre os mecanismos de prestação de contas sobre proliferação nuclear e a suspeita de desenvolvimento de armas de destruição em massa, de forma que a United Nations Monitoring, Verification and Inspection Commission (UNMOVIC) e a Agência Internacional de Energia Atômica (AIEA) teriam o direito de determinar o número de inspetores necessários para o acesso ao país e realizar seu trabalho.

2 No momento da invasão, alguns membros (e não-membros) inclusive pediram a suspensão daquilo que eles descreveram como "agressão ilegal" ao Iraque, conforme o Press Release de 27 de março de 2003 do CSNU, disponível em <www.un.org/press/en/2003/sc7707.doc.htm> acesso em 04/09/2021.
} 
a ocupação estadunidense no país buscou um processo de reconstrução de um estado (statebuilding) com semelhanças às operações de paz (Williams, 2009; Newman et al., 2009; Malone; Chitalkar 2013; Dodge, 2013). Outros ressaltam as particularidades do caso iraquiano (bem como afegão em 2001) como modelo intervencionista norte-americano de reconstrução de nação (nationbuilding) (Fukuyama, 2006; Egan, 2007). Longe do nosso propósito ser adequar ou categorizar os modelos de intervenções contemporâneas e enquadrar o caso iraquiano - esforço para além do escopo deste artigo -, podemos afirmar que existe um elemento que conecta todas essas práticas intervencionistas: a premissa liberal internacionalista de responsabilidade humanitária como artifício legitimador das ações intervencionistas. Em razão dessa similaridade, resgatamos os esforços de diferentes analistas dedicados a compreender as intervenções internacionais e sua relação com a criminalidade.

Identificamos uma ampla literatura que avalia a relação entre intervenções internacionais e criminalidade, cujas contribuições podem oferecer caminhos para futuros estudos sobre o Iraque. Classificamos esse corpo bibliográfico a partir de interpretações distintas em torno da relação entre reconstrução de Estados e criminalidade, as quais buscamos sistematizar.

Um primeiro conjunto de trabalhos, mais alinhados à perspectiva oferecida pelos tomadores de decisão, compreende a criminalidade como obstáculo ao estabelecimento da paz e da estabilidade no país ocupado (p.e. Cockayne, 2009; Caparine, 2009). Se o objetivo buscado pelas intervenções pós-conflito diz respeito à reconstituição da autoridade estatal, os altos índices de criminalidade representam uma das suas mais importantes afrontas e desafios a esse fim. O contrário também é válido: espera-se que a consolidação da autoridade estatal seja acompanhada da redução dos índices de criminalidade. Na avaliação de Williams $(2009$, 129) "o crime organizado no Iraque não é um caso isolado ou uma anomalia; está integralmente relacionado com o colapso do Estado". Nesses termos, há uma relação de competitividade entre o processo de reconstrução de Estados e a criminalidade.

Um segundo grupo de trabalhos, crítico ao primeiro, busca apresentar nuances e contradições à contraposição dicotômica entre o legal e o ilegal, destacando as relações de complementariedade possível entre o processo de reconstrução de Estados e a criminalidade (p.e. Andreas, 2009; Berdal, 2009; Hansen, 2014). Isso significa antecipar que certas atividades criminosas podem se beneficiar do processo de reconstrução, da mesma maneira que o Estado em consolidação também pode se fortalecer em função dos ganhos produzido por certas atividades criminosas. Para essa abordagem, portanto, não é nada surpreendente que os processos de reconstrução de Estado sejam acompanhados do aumento da criminalidade (Looney, 2006).

Em torno do caso da ocupação do Iraque iniciada em 2003, o artigo coloca em diálogo essas duas abordagens. Ao longo do texto, levantamos trabalhos dedicados a compreender as especificidades do processo iraquiano e trabalhos que nos oferecem ferramentas analíticas e possibilidades de interpretações alternativas a partir de pesquisas realizadas em torno de outros estudos de caso. Elaboramos os argumentos apresentados no artigo a partir de uma pesquisa e sistematização da literatura especializada no tema. Privilegiamos, portanto, a coleta e análise de trabalhos acadêmicos, ainda que haja menção a documentos produzidos por organizações internacionais e governos. 
A literatura está bastante concentrada na primeira década de 2000, reagindo ao crescimento das operações de paz desde a década anterior e aos primeiros esforços de reconstrução do Iraque, período em torno do qual essa revisão de literatura se concentra. Cabe destacar, contudo, que há um novo conjunto de análises mais recentes que resgatam essa problemática a partir do nexo entre criminalidade e terrorismo, muitas delas em reação à ascensão do Estado Islâmico (ISIS) no país (p.e. ONU, 2019; Stanfield, 2019; Johnston et al., 2019; Shelley, 2020).

Para desenvolver esse raciocínio, o artigo está estruturado em quatro partes, além desta introdução. No primeiro tópico, apresentamos as distintas formas de intervenção internacional e de qual maneira interpretamos ser adequado compreender o caso da invasão e ocupação do Iraque em 2003. No segundo tópico, apresentamos o processo social em torno do qual os trabalhos se debruçam, apontando para diferentes interpretações que têm sido oferecidas pela literatura especializada. Aqui, portanto, sistematizamos os trabalhos dedicados a interpretar o aumento da criminalidade que se seguiu à ocupação norte-americana no Iraque. Na terceira parte, apresentamos as contribuições oferecidas pela literatura sobre intervenções internacionais e criminalidade, lançando luz à possibilidade de pensar interpretações alternativas e inovadoras para o processo iraquiano. Classificamos essa literatura em dois grupos em função da interpretação distintas sobre a relação entre reconstrução de Estado e criminalidade, uma primeira avaliando-a em termos de competitividade e uma segunda que identifica contradições e uma possível complementaridade entre ambos. Por fim, apresentamos algumas conclusões que emergem do diálogo entre tais abordagens, propondo novos caminhos às pesquisas dedicadas a compreender a criminalidade no Iraque pós-guerra.

\section{A ocupação do Iraque: como tipificar o seu modelo de intervenção?}

Após a II Guerra Mundial, com o estabelecimento de um novo consenso internacional - balizado nas conferências de paz e no estabelecimento de um sistema de novas instituições internacionais - estabelece-se uma correlação entre as práticas intervencionistas e a compreensão das justificativas cabíveis para empreendê-las. Assim, o humanitarismo ${ }^{3}$ emerge inserido em uma agenda intervencionista que domina as relações internacionais (Fassin, 2012), tendo como principal fonte normativa o respaldo da ONU, por meio de suas operações de paz.

\footnotetext{
3 Didier Fassin $(2012,1)$ utiliza "a expressão 'governo humanitário' para designar a implantação de sentimentos morais na política contemporânea. "Governo" aqui deve ser entendido em um sentido amplo, como o conjunto de procedimentos estabelecidos e ações realizadas para gerir, regular e apoiar a existência de seres humanos: o governo inclui, mas excede a intervenção do Estado, administrações locais, internacionais, órgãos e instituições políticas em geral. Da mesma forma, 'humanitário' deve ser entendido em um sentido ampliado, pois conota ambas as dimensões abrangidas pelo conceito de humanidade: por um lado, a generalidade dos seres humanos que compartilham uma condição semelhante (humanidade), e, por outro, um movimento afetivo que atrai os humanos para seus semelhantes (humanidade). A primeira dimensão forma a base para uma reivindicação de direitos e uma expectativa de universalidade; a segunda cria a obrigação de dar assistência e atenção aos outros, (...) a articulação entre razão e emoção que define os sentimentos morais.
} 
Esse fenômeno significa a transição do tipo de ocupação internacional militar para novas formas de ocupação conhecidas como "intervenções humanitárias". Desde então, a estrutura da segurança internacional coletiva, instituída pelo regime da Carta das Nações Unidas em 1945 se tornou mais complexa, a fim de responder aos novos problemas e às novas demandas do mundo pós-Guerra Fria (Chandler, 2004). Argumentam as grandes potências ser necessária uma resposta à potencial difusão de conflitos civis em Estados "não-liberais". Para esse fim, foram formuladas operações denominadas "peacebuilding pós-conflito", cujo propósito declarado era impedir a continuidade do estado de violência pós conflito. Esse modelo foi mobilizado em oito Estados destruídos pela guerra: Namíbia, Camboja, El Salvador, Nicarágua, Angola, Ruanda e Bósnia (Paris, 1997).

Nota-se na literatura, a substituição do termo ocupação para termos como operações de paz, Statebuilding, Peacebuilding, intervenções humanitárias, entre outras denominações semelhantes, que na prática são ocupações praticadas por potências internacionais, mas com o respaldo legal e bandeira da ONU (Ratner, 2005). Conforme indica Amaral (2019), em oposição às ocupações internacionais do passado, cuja característica imperial de expansão territorial e poder eram declaradas, as ocupações internacionais contemporâneas se caracterizam pelo "curto" período de ocupação, pois seriam ações provisórias (Paris, 2010); por sua natureza multilateral (Harris, 2006); e por objetivos pautados no humanitarismo, e não numa política de poder (Paris, 2010; Fox, 2008).

Nas Relações Internacionais, emergem nos anos 1990 uma literatura sobre operações de paz (Statebuilding, Peacebuilding, Peace-enforcement, etc.), como parte da grande área de Estudos de paz, ou Paz Liberal, como denominam seus críticos (Chandler, 2004; Pureza, 2018; Newman et al., 2009). A noção de paz liberal se refere à ideia de que certos tipos de sociedades (liberalmente constituídas) tendem a ser mais pacíficas, nos âmbitos doméstico e intranacional (Newman et al., 2009). Desta forma, as ocupações internacionais ganham legitimidade perante a comunidade internacional com base no discurso da paz liberal, embasado na razão humanitária (Fassin, 2012). Assim, denuncia Chandler (2004), os defensores desse modelo, sobretudo as potências ocidentais, reafirmam que as normas internacionais voltadas à proteção aos direitos individuais prometem uma estrutura de paz, engendrada por esforços de segurança coletiva.

Ainda que tal discurso predomine, nem todas as práticas intervencionistas são caracterizadas pelo "selo" da ONU. Na verdade, grande parte das intervenções são implementadas sem seu reconhecimento, geralmente desempenhadas por coalizões internacionais institucionalizadas - como é o caso da Organização do Tratado do Atlântico Norte (OTAN) no Kosovo, em 1998 - ou coalizões pontualmente estabelecidas - como é o caso da coalizão de forças multinacionais para expulsar os iraquianos do Kuwait, em 1990. Ainda assim, buscam se apoiar no mesmo discurso humanitário baseado em premissas ideológicas liberais internacionais (Chandler, 2004; Williams, 2009; Newman et al., 2009).

A ocupação do Iraque - envolvendo eleições, processos constitucionais, ajuste econômico e fortalecimento institucional - reproduziu o mesmo padrão, mas desafiou a legitimidade do projeto mais amplo de construção da paz (Chitalkar, Malone, 2013; Dobbins et al, 2009; Harris, 2006; Newman et al., 2009; Paris, 2004). Ela envolveu um processo peculiar no âmbito do CSNU que, por meio da Resolução 1483, reconheceu os EUA e a Grã-Bretanha como potências ocupantes, ou autoridade provisória do Iraque no período imediatamente após 
a derrubada do Regime de Saddam Hussein. A primeira grande disparidade com os modelos de ocupação das operações de paz se refere à liderança do projeto de statebuilding do Iraque. A ocupação do Iraque não foi realizada por um mandato da ONU. Na realidade, a ONU autorizou a ocupação anglo-americana a posteriori, denominando ambas as potências autoridades provisórias do Iraque.E apesar de se tratar de uma ocupação multilateral, todo aparato destinado para reconstrução, ajuda humanitária e estabilização política foi articulado pelo governo dos EUA (Chitalkar, Malone, 2013).

Por fim, outro debate levantado pela literatura apontou para o uso do termo nationbuilding (construção de nação) como modelo particular do processo de reconstrução do Iraque (Fukuyama, 2006; Egan, 2007). Estes afirmaram que o propósito dos EUA no Iraque (como no Afeganistão) foi não somente construir estruturas institucionais ao Estado, mas também introduzir à sociedade ocupada novos conjuntos normativos, comportamentais, morais associados aos mesmos das forças ocupantes. Construir uma nova concepção nacional através de dois eixos: Reconstrução e Desenvolvimento. A reconstrução refere-se à restauração de sociedades dilaceradas pela guerra, enquanto desenvolvimento refere-se à criação de novas instituições e à promoção do crescimento econômico, transformando a sociedade em algo que não era antes (Fukuyama, 2006).

Diante deste corolário, neste artigo escolhemos o uso do termo statebuilding, pois ele qualifica e destaca o aspecto que nos interessa da intervenção no Iraque. A saber: os mecanismos de reconstrução das estruturas do Estado iraquiano pósSaddam, dando destaque aos mecanismos institucionais de segurança do país, especificamente para o combate à criminalidade. Evidentemente, a intervenção no Iraque não se trata de uma operação de paz (e suas tipologias derivativas) da ONU. Agora, nos interessa compreender de que maneira a literatura interpreta o processo de construção de artifícios institucionais do Estado para o combate à criminalidade. Para esse propósito, olhar para a ocupação do Iraque como statebuilding parece adequado. Por fim, ainda que existam particularidades nos processos intervencionistas contemporâneos, partimos da interpretação de que o desenvolvimento de mecanismos de combate à criminalidade em intervenções internacionais é particularmente semelhante e parte da mesma premissa liberal internacionalista de criar instituições que transformem ou reformem o Estado incapaz de fazê-lo autonomamente.

\section{Leituras sobre o processo de reconstrução e criminalidade no Iraque}

Estudiosos e decisores políticos identificaram um aumento significativo das atividades criminosas no Iraque após a ocupação em 2003 (p.e. CAP, 2003; UNODC, 2003; Harring; Rangwala, 2005; Williams, 2009). O tráfico de drogas, de artefatos históricos e de pessoas são destacados pela literatura, assim como os produtos de contrabando como petróleo, ligando estreitamente o país a redes de crime transnacional.

Desde a ocupação em 2003, o Iraque se integrou mais profundamente no comércio informal mundial de armas, pornografia e drogas ilegais, incluindo heroína, haxixe, cocaína, tranquilizantes, antidepressivos e outros medicamentos, com drogas saqueadas e roubadas de hospitais e farmácias ou entrando pelo Irã, Afeganistão, Arábia Saudita e Síria. O contrabando de artefatos antigos iraquianos 
se tornou outra prática difundida para servir o mercado de arte global centrado em torno de Genebra, Tóquio, Nova York e Londres. O Iraque está também a ser integrado na indústria do sexo global. Os traficantes iraquianos e egípcios sequestram e vendem mulheres locais para a escravidão da prostituição, às vezes levando-as para a Síria e para bordéis no lêmen (Harring; Rangwala, 2005). Ainda, em razão de possuir uma economia fiduciária (cash economy), o latrocínio, roubo e furto também se tornaram comuns e estima-se que, em média, cerca de um milhão de dólares por mês foi roubado sob a mira de uma arma. De tal forma que em 2007, Bagdá foi considerada a capital mundial do roubo a bancos (Williams, 2009). Outras fontes de lucro foram relacionadas a sequestros, extorsão e, principalmente, o contrabando de petróleo, já comum anteriormente à invasão (Harring; Rangwala, 2005). Na avaliação de Williams (2009), desde que o Iraque foi submetido a sanções econômicas como punição à invasão ao Kuwait em 1990, o contrabando se tornou o meio de comercialização de mercadorias mais importante do país.

As primeiras avaliações da CAP que indicavam uma preocupação com os altos índices de criminalidade aparecem já no início do processo de reconstrução (CAP, 2004; 2003). "O Iraque não está apenas enfrentando ataques diários de terroristas, o crime organizado está florescendo na desordem criada após a guerra", dizia o relatório (CAP, 2003). Em outubro de 2003, as marinhas norte-americana e britânica interceptaram muitos veículos rodoviários e pequenos navios contrabandeando petróleo iraquiano direcionados ao mercado global. Forças militares britânicas calculavam que a quantidade de petróleo que estava sendo contrabandeada do Iraque semanalmente para o Kuwait e os Emirados Árabes Unidos havia subido para cerca de 3.000 toneladas em dezembro de 2003. Autoridades iraquianas estimam que até $25 \%$ do petróleo refinado iraquiano foi exportado de maneira ilegal em janeiro de 2004. (Herring; Rangwala, 2008, 678).

Atento a esses dados, o Escritório das Nações Unidas sobre Drogas e Crime (UNODC) enviou uma missão ao Iraque em 2003 em busca de informações mais precisas sobre a criminalidade do país. A missão foi atendida por um pedido do Representante Especial do Secretário-Geral do Iraque (SRSG), Sérgio Vieira de Mello. Em sua declaração perante o CSNU em 22 de julho de 2003, ao descrever o objetivo da missão do UNODC, Sergio de Mello enfatizou a necessidade de examinar como as estratégias podem ser desenvolvidas para lidar com diferentes tipos de crime organizado, particularmente o tráfico de drogas. O principal objetivo da missão era avaliar a extensão do crime organizado e do tráfico de drogas e revisar o atual quadro jurídico e institucional para fazer recomendações apropriadas (UNODC, 2003). Como parte desses esforços, em 2008, o Iraque tornou-se signatário da Convenção das Nações Unidas contra o Crime Organizado (Convenção de Viena) de 2000.

Nesse mesmo sentido, recomendações da ONU apontaram que "a reconstrução da Força Policial Iraquiana (IPF) é considerada uma prioridade importante e urgente pela CPA e pelo Conselho de Governo em seus esforços para trazer segurança e estabilidade ao Iraque" (ONU, 2003, 17). Em direção a esse fim, a CPA mobilizou esforços para reconstruir as forças policiais, oferecer treinamento às polícias e equipamento, estabelecer unidades de investigação e reformar todo o setor de justiça e segurança (ONU, 2003; USA, 2009). A redução da criminalidade no Iraque apresentava-se, portanto, como um resultado esperado do processo de reconstrução. 
Atentos a esse processo político, pesquisadores dedicados ao tema formularam diferentes explicações para o resultado inesperado: o aumento da criminalidade no Iraque. As diferentes interpretações convergem na identificação de um mesmo fenômeno: o processo de reconstrução do Iraque vinha sendo acompanhado de um aumento da criminalidade, sobretudo em sua dimensão transnacional, no Iraque.

Um primeiro conjunto de atores assume o Iraque como um Estado falido, colapsado ou fragilizado, cuja relação com o mercado ilegal tornou-se simbiótica. Nesses termos, avaliam que a criminalidade é um fator de risco relevante ao projeto de reconstrução do Estado e que deveria ser mais profundamente endereçado pelas autoridades responsáveis (p.e.Williams, 2009; Henderson, 2005). Um segundo conjunto de autores quebram a dicotomia entre o Estado e a criminalidade. Nesse sentido, a criminalidade nem sempre se apresenta como um entrave à reconstrução do Estado, mas pode ser também o próprio resultado desses esforços políticos, andando lado a lado com o projeto de reconstrução (Harring; Rangwala, 2005; Looney, 2006).

Williams (2009) afirma que o Iraque antes da ocupação, sob a administração de Saddam Hussein, era um "estado criminoso", cuja lógica de comportamento não era simplesmente a exploração de organizações criminosas independentes, mas o próprio estado centralizando o controle sobre muitas atividades criminosas. Nesse sentido, usa-se o termo "Estado pária" (rogue state) para se referir a Estados cuja conduta é considerada fora das normas internacionais de comportamento por parte ou por toda a comunidade internacional. Se o mercado ilegal já estava imbricado na economia iraquiana, a instabilidade trazida pela intervenção de 2003 só piorou esse quadro (Williams, 2010).

Nesta visão, o processo de intervenção para mudar, ou reconstruir, um Estado se faz justificada, devendo assumir o combate à criminalidade e o restabelecimento da ordem social alinhada ao direito internacional como metas fundamentais. $\mathrm{Na}$ avaliação de Williams (2009), faltava atenção por parte autoridades interventoras, que, naquele contexto, estavam mais preocupadas com a dimensão política da ocupação e menos atentas à importância do controle sobre a criminalidade, cujo crescimento certamente representaria um potencial entrave à reconstrução do Estado iraquiano.

Isso porque, ele afirma, o contrabando foi praticamente dominado por grupos insurgentes que obtêm grande parte de seu financiamento do contrabando de petróleo, tanto como participantes diretos quanto como beneficiários de taxas de extorsão cobradas de caminhões-tanque (Shelley, 2020). Em 2006, o ministro das finanças do Iraque estimou que os insurgentes estavam obtendo $40-50 \%$ dos lucros do contrabando de petróleo (Williams, 2009). Essa mesma intepretação foi defendida por Kan (2007), que destacou o papel do mercado ilegal de drogas como fonte de recursos financeiros para compra de armas, equipamentos e influência política que alimentam a insurgência em curso.

Faltavam mecanismos de controle e accountability dentro das próprias estruturas governamentais, já corrompidas, na avaliação desses autores. Segundo Wahab $(2006,54)$, em 2005 foram evidenciados casos de contrabando de petróleo entre membros do próprio ministério, resultando na demissão de 450 funcionários sob a suspeita de roubavam e vendiam combustível para o exterior. 
A relação entre fragilidade estatal e criminalidade é evidente nessa leitura, que é compartilhada também com McAllister (2005). Assim, o autor argumenta que o crescimento do roubo de antiguidades iraquianas indicava que os tentáculos do crime organizado transnacional já envolviam grande parte do Estado, e o próspero mercado para os tesouros nacionais poderia oferecer a esses grupos nascentes o mercado, capital e motivação para expandir ainda mais e continuar a abusar da frágil estrutura política iraquiana.

De maneira alternativa, um segundo grupo mais restrito de autores identificou que o crescimento da criminalidade no Iraque e o processo de reconstrução do Estado andaram lado a lado. Isso porque a internacionalização e a liberalização econômica do Iraque, promovidas pela CAP, significaram abertura da economia ao mercado transnacional, viabilizando a internacionalização de atividades econômicas informais (Harring; Rangwala, 2005). Ou seja, as mesmas estruturas que viabilizaram a transnacionalização do mercado legal também possibilitaram o acesso de grupos ilegais e informais iraquianos ao mercado global. "Esta globalização de baixo demonstra que o Iraque não é apenas o objeto passivo da globalização de cima", afirmam os autores (Harring; Rangwala, 2005, 681).

Sob essa avaliação, a remoção do regime de Saddam e as ações da CAP apresentaram uma série de oportunidades e restrições que determinaram a maneira pela qual os grupos ilícitos se mobilizaram e geraram novas oportunidades de economia informal e criminalidade, como também indica Looney (2006). Em suma, reformas da economia e do sistema de justiça promovidas pela CAP, a dissolução do exército nacional iraquiano e a ambivalência da coalizão em relação à ascensão das milícias apresentaram uma nova oportunidade para economia informal ganhar corpo e seus agentes expandirem sua influência e controle de recursos.

Ambas as interpretações se originam de uma agenda de pesquisa mais ampla e mais consolidada que busca compreender a relação entre criminalidade e intervenções internacionais. A partir dela, buscaremos identificar construções interpretativas que possam auxiliar no amadurecimento das concepções sobre o caso iraquiano, destacando, sobretudo, as relações de complementaridade entre criminalidade e reconstrução de Estado, tornando menos improvável o diagnóstico identificado pelos analistas supracitados.

\section{Um caso não tão incomum: o impacto das intervenções internacionais sobre a criminalidade}

O problema da criminalidade tem cada vez mais sido levado em consideração por estudiosos e atores políticos dedicados a processos de paz e reconstrução de Estados, o que se aplica às operações de paz da ONU ou outras modalidades de ocupação e intervenção conduzidas pelas grandes potências, como é o caso do Iraque.

Se as primeiras intervenções internacionais da ONU se dedicavam a estabelecer acordos de paz entre as partes em conflito, desde os anos 1990 elas têm se voltado à construção de uma chamada paz positiva, voltada às condições com potencial desestabilizador daquelas sociedades. Tal processo pressupõe a reconstrução do Estado (statebuilding), seu exercício da autoridade autoridade e capacidade de garantir o monopólio do uso legítimo da força. As reformas propostas pelas intervenções visam moldar as instituições estatais, garantir 
a legitimidade e autoridade do governo recém-empossado, estabelecer condições para a prosperidade de uma economia liberal. Na esteira desse processo, a segurança pública e a questão da criminalidade apresentaram-se como um ponto fulcral. A criminalidade emerge, nesse plano, como um potencial obstáculo, na medida em que burla a autoridade e as leis daquele Estado, desacredita a autoridade policial, circula dinheiro paralelamente à economia formal e, por vezes, promove a violência, minando o monopólio do uso da força por parte do Estado (Hansen, 2014).

Estudiosos, como Boutellis e Tiélès (2019) notam que grande parte das operações de paz da ONU operam em contextos significativamente afetados pelo crime organizado. Em busca de compreender os novos cenários de conflitualidade, Mary Kaldor (2012) reconhece que a imprecisão, que se apresenta nesses contextos, da separação dicotômica entre violência de guerra e de criminalidade que opera nesses contextos. Segundo a autora, as chamadas "novas guerras" se fundem com a criminalidade na medida em que operam em contextos de fraqueza ou ausência de autoridade estatal legítima.

Segundo esse grupo de pesquisadores, a criminalidade tende a prosperar, sobretudo, em conflitos que se desenrolam no que denominam como Estados "falidos", "fracos" ou "colapsados". A ausência de instituições estatais legítimas e responsáveis oferece oportunidade à autoridade exercida por grupos violentos privados e predatórios. Nesse contexto, apresenta-se uma espécie de competição pela proteção oferecida por um Estado enfraquecido e por grupos criminosos locais e transnacionais (Cockayne, 2009). A criminalidade torna-se uma oportunidade econômica e fonte de receita de grupos armados em contextos de conflito, incluindo grupos armados e terroristas (Caparine, 2009; ONU, 2019). No Afeganistão, por exemplo, o tráfico de ópio é considerado pelas autoridades uma importante fonte de renda para o Talibã (Felbab-Brown, 2009; Kuhn et al., 2013). Nesse sentido, aquelas atividades criminosas que acabam por servir como fonte de acesso a armas e dinheiro para grupos armados não estatais envolvidos no conflito impactam significativamente no processo de paz e reconstrução (Caparine, 2009; Wennmann, 2011).

Para Williams (2009), o combate ao crime organizado deve ser fundamental para a missão dos EUA no Iraque, já que fomenta a violência entre grupos que compõem o conflito. Assim, a recomposição da autoridade Estatal apresenta-se como a melhor maneira de combater o crime, da mesma maneira que a criminalidade se apresenta como um dos mais duros desafios da reconstrução dessa mesma autoridade (Caparine, 2009, Kaldor, 2012). O papel das operações de paz seria, portanto, encontrar uma resolução para a competição pela proteção em favor de um modo protetivo liberal oferecido pelo processo de reconstrução (Cockayne, 2009). Avalia-se que as atividades criminosas produzem um efeito debilitante na consolidação da paz e reconstrução estatal, minando o estabelecimento da estabilidade, da boa governança, do Estado de direito e da reconstrução econômica (Williams, 2009, p.116). Assim, o processo de paz e a criminalidade apresentamse como forças competidoras.

Essa avaliação passa a ser também incorporada pela ONU. O "Report of the Highlevel Panel on Threats, Challenges and Change", um documento assinado em 2004 pela instituição, reconhece o crime transnacional como uma ameaça à segurança internacional. Nas palavras de Kofi Annan, Secretário Geral das Nações Unidas, "as atividades criminosas organizadas minam os esforços de construção da paz e 
alimentam muitas guerras civis através do comércio ilícito de mercadorias de conflito e armas leves" (ONU, 2004, 21)". O World Development Report publicado pelo Banco Mundial em 2011 reforça essa posição, destacando que a criminalidade pode se impor como um obstáculo ao desenvolvimento econômico e à construção da paz (World Bank, 2011). No Afeganistão, o Conselho de Segurança avaliou a relação entre o terrorismo e o tráfico de drogas como importante entrave à construção da paz, reforçando o nexo do narco-terrorismo (Boutellis; Tiélès, 2019). O órgão, também responsável pela aprovação e condução das operações de paz da ONU, publicou um Security Council Presidential Statement (PRST) em 2010 registrando seu reconhecimento de que o tráfico de drogas e o crime transnacional representam uma séria ameaça à segurança dos Estados, convidando o Secretário Geral da ONU a considerar tais problemas nas análises, prevenção e solução para conflitos internacionais (ONU, 2010). A reconstrução do Estado e da autoridade estatal e o combate ao crime apresentam-se como a estratégia decisiva para obstruir a capacidade de atores não estatais violentos.

Espera-se, por sua vez, que uma operação de paz, ou statebuilding, bem-sucedido também tenha como resultado a redução da criminalidade, que tem no conflito solo fértil de prosperidade. No caso do Mali (MINUSMA), o Secretário Geral da ONU afirmou em um relatório do Conselho de Segurança que "enquanto foram tomadas medidas positivas para a implementação do acordo de paz pelas partes signatárias, houve um aumento no número e disseminação geográfica de atividades de grupos extremistas e terroristas e redes de crime organizado", grupos estes que não apenas operam paralelamente à missão, mas rivalizam e exercem violência sobre ela (ONU, 2015a).

Essa fórmula, contudo, é mais complexa do que parece. Esse processo pode ser violento. No caso do Haiti, Cockayne (2009) relata que a entrada da missão de estabilização da ONU em 2004, a MINUSTAH, foi acompanhada de um aumento da violência em Port-au-Prince e nos centros urbanos resultante da competição estabelecida entre os grupos armados criminosos e as forças da missão e do Estado em construção. Em outros casos, as respostas que visam a estabilização muitas vezes apresentam resultados insatisfatórios pela falta de capacidade da ONU de impor as reformas necessárias para o combate à criminalidade, por vezes em função dos interesses políticos que possam estar associados a isso (Gavigan, 2009).

Os dados que indicam o crescimento da criminalidade também podem ser nebulosos. Em muitos casos, o que assistimos é à criminalização de grupos armados envolvidos no conflito por parte da autoridade que se estabelece na intervenção. Como aponta Kan (2007), "paras nações da coalizão e para o governo iraquiano, ser um insurgente é ser um criminoso. Mas nem todo criminoso é insurgente". Nesse mesmo sentido, o aumento da criminalidade também pode estar relacionado à disputa de narrativas políticas e à criação dos novos estatutos criminais produzidos pelas autoridades políticas que se colocaram no poder, da mesma maneira como pode ser explicado pelo crescente esforço dos Estados em controlar certos trânsitos de bens e pessoas, elevando o tema a uma posição prioritária das autoridades (Andreas, 2011).

Um olhar mais acurado sobre dados coletados até esta etapa da pesquisa também revela que os Estados Unidos denunciavam o governo iraquiano por não produzirem dados sobre a criminalidade transnacional no país (USA, 2009). Isso significa que é impreciso dizer que o crime transnacional cresceu após 
a ocupação, quando os dados passaram a ser coletados por autoridades norteamericanas e pelo Escritório das Nações Unidas para Drogas e Crime (UNODC). O que certamente cresceu foi o controle estatal sobre tais fluxos, na medida em que foram desenvolvidas estruturas de policiamento, coleta de dados e controle sobre tais atividades como parte do processo de ocupação. Essa questão nos leva a refletir sobre como a dicotomia entre o legal e o ilegal por vezes tem um poder explicativo limitado, sobretudo em contextos de conflito, onde parte importante da economia se realiza no campo da informalidade.

Nesse sentido, a ocupação do Iraque viabilizou a internacionalização das políticas norte-americanas de combate ao crime - sobretudo em sua dimensão transnacional - neste país, que passou a receber assistência e treinamento policial visando este fim. Ao mesmo tempo em que os fluxos transnacionais ilegais cresciam a partir do Iraque, os Estados Unidos também promoviam a criminalização e o recrudescimento do controle sobre certos fluxos no país. É comum que processos de reconstrução de Estados sejam acompanhados da reestruturação das forças policiais, do sistema de justiça e de mecanismos que visem o controle da criminalidade transnacional (Nadelmann, 1993; Goldsmith, Sheptycki, 2007). Para citar alguns exemplos, a partir de 2003, o Departamento de Justiça dos Estados Unidos passou a conduzir programas de treinamento policial, voltados a temas tão diversos quanto sistema prisional, combate à corrupção, segurança das fronteiras, justiça forense e investigações no campo judicial. De 2005 a 2010, - Departamento de Estado conduziu um Programa de Educação da Polícia do Iraque (IPEP) visando oferecer treinamento às polícias iraquianas com a finalidade de profissionalizá-las (USA, 2005-2010).

Além disso, a criminalidade e a reconstrução de Estado nem sempre são fenômenos que se enfraquecem mutuamente e essa relação é mais ambígua do que parece (Andreas, 2009). Há casos em que o crime organizado se beneficia de períodos de transição da guerra para a paz, conseguindo estabelecer laços e relações simbióticas com as elites políticas locais e com as redes transnacionais de criminalidade (Berdal, 2009; Hansen, 2014). Nesse sentido, nem sempre a criminalidade e as autoridades estatais são adversárias e colidem em seus objetivos. Em alguns casos, é possível que elas colaborem entre si (Sheye, 2015).

Partindo dessas nuances e contradições, assumimos então a interpretação de um segundo grupo de pesquisadores que não avalia a criminalidade apenas como mais um fator de risco para a estabilização ou uma falha do processo de reconstrução. De forma aparentemente contraditória, demonstram haver uma tendência ao aumento da criminalidade em situação de recuperação pós conflito, intervenções internacionais e processos de reconstrução de Estado (Boer, Bosetti, 2015; Cheng, 2013). Esse diagnóstico dissolve alguns binarismos típicos deste campo de estudo, que opõem a paz ao conflito, o ilegal ao legal, o estatal ou não estatal, como identificam Cockayne e Lupel (2009).

Há um conjunto de autores interessados em investigar a economia política da guerra, destacando a multiplicidade de atores que se articulam transnacionalmente em torno das oportunidades lucrativas que ela gera e que, portanto, sustentam seu prolongamento. Mercados de artes, petróleo, diamante e armas são alguns dos muitos setores que puderam se beneficiar economicamente da guerra (Berdal Malone, 2000; Duffield, 2000; Coolier; Hoeffley, 2004). Os processos de paz e a chamada reconstrução não só se articulam sob essa estrutura, como oferecem novas oportunidades para esse mercado. A reconstrução 
do Iraque contou com a contratação, por parte do governo norte-americano, de empreiteiras, empresas militares e de segurança privada e a entrada de corporações do ramo do petróleo no país. Como consequência, novas oportunidades também se apresentam também ao mercado informal ou ilegal que se articula doméstica, mas também transnacionalmente, atingindo mercados legais e ilegais dos países desenvolvidos.

Para Buer e Bosetti (2015), os atores envolvidos na criminalidade podem agir como desestabilizadores ou aliados no processo de reconstrução do Estado. Ainda que as autoridades tenham como princípio formal combate o mercado ilícito, em muitos casos esse mesmo mercado auxilia no abastecimento de itens de primeira necessidade à população, compensando os níveis insuficientes de ajuda, facilitando a estabilização de uma condição de conflito (Andreas, 2006). As atividades criminosas "também podem apoiar o processo de paz. Em alguns casos, o fim do conflito pode fornecer um grau de estabilidade e previsibilidade que torna os negócios ilícitos lucrativos" (Boer, Bosetti, 2015). Esse é o caso da Bósnia, onde a relação entre criminalidade e operação de paz foi mais simbiótica do que predatória. Nesse caso, o mercado informal e ilícito contribuiu para que alguns objetivos das operações de paz fossem alcançados, assim como as operações de paz contribuíram com a prosperidade de setores do mercado ilegal (Andreas, 2009). No caso do Afeganistão, ainda que o tráfico do ópio seja politicamente associado ao Talibã e, portanto, alvo importante da intervenção, estudiosos apontam como não só a produção de ópio aumentou no país após a ocupação norte-americana e operação de paz da ONU, como esse mercado atendeu a interesses de uma importante elite política aliada do processo de reconstrução de Estado (Kuhn et al., 2013, Mercille, 2013).

Os processos de paz podem oferecer condições à prosperidade das atividades ilegais ou informais e um clima de estabilidade e previsibilidade bom para os negócios, lícitos e ilícitos (Andreas, 2009), além de injetar dinheiro na economia local, por meio de empréstimo ou abertura de empregos, por exemplo, estimulando o consumo de bens legais e ilegais (Andreas, 2009). A adoção de uma nova moeda também pode facilitar o acesso de atores ilícitos locais ao mercado internacional (Andreas, 2009). Nesse sentido, se o objetivo da ocupação do Iraque é abri-lo para os negócios, o resultado esperado é que o país também ofereça oportunidades ao crime transnacional. Alguns enquadram este processo como consequência natural da liberalização econômica do país o desenvolvimento paralelo de fluxos ilícitos, ou seja, a criação de uma economia de mercado ou sistema de livre iniciativa quando os agentes econômicos agem de forma livre é comum o desenvolvimento de sistemas econômicos paralelos, fora da "regra do jogo" econômico posto (Herrig, Rangwala, 2005, Williams, 2009).

Indivíduos que compõem a ocupação ou a operação de paz também podem se utilizar de sua posição privilegiada para se beneficiar de atividades ilegais ou até se tornarem cúmplices, como atores de suborno, transportadores, informantes, intermediários, facilitando o comércio entre as partes em guerra e, às vezes, até os consumidores do mercado ilício (Andreas, 2009). No caso do Iraque, podemos mencionar a alta no contrabando de artefatos antigos iraquianos é outra prática difundida para servir o mercado de arte global centrado em torno de Genebra, Tóquio, Nova York e Londres (Herring; Rangwala, 2005). Andreas (2009) menciona que, quando as forças da OTAN se estabeleceram na Bósnia, ativistas alegavam que era possível dirigir pelas ruas e saber quais eram as forças internacionais 
responsáveis por aquela região pelo nome que as casas de prostituição carregavam. Ou seja, as forças interventoras também trazem demandas para o mercado ilegal local. O Iraque está também a ser integrado na indústria do sexo global. Os traficantes iraquianos e egípcios sequestram e vendem mulheres locais para a escravidão da prostituição, às vezes levando-as para a Síria e para bordéis no lêmen. As prostitutas do Iraque agora têm uma grande base de clientes na forma de centenas de milhares de funcionários civis e militares estrangeiros ricos em dólares (Herrig, Rangwala, 2005).

Os diferentes exemplos trabalhados nesse tópico nos demonstram que a relação entre criminalidade e reconstrução de Estados é mais ambígua do que parece. O aumento da criminalidade nas intervenções internacionais, como é o caso da ocupação do Iraque, podem ser explicadas pelo esforço em criminalizar, reprimir e coletar dados sobre práticas que já estavam em curso na sociedade, mas também porque as intervenções podem não só criar um ambiente propício para a prosperidade de certas atividades criminosas, como pode depender de algumas delas ao longo do processo.

\section{Conclusão}

O presente artigo se propôs a sistematizar as interpretações que foram levantadas sobre o caso iraquiano à luz daquilo que vem sendo desenvolvido, paralelamente, por estudiosos dedicados a compreender a relação entre intervenções internacionais e criminalidade. Com isso, buscamos apontar para trajetos interpretativos alternativos para o caso do Iraque. As pesquisas sobre o crescimento da criminalidade no Iraque após a ocupação norte-americana em 2003 no Iraque divergem quanto à interpretação de suas causas. Na maioria dos casos, alinham-se às posições oferecidas pelos atores governamentais, como Estados Unidos, ou supranacionais como a Nações Unidas, que estabelecem uma relação de oposição entre criminalidade e reconstrução de Estado.

Há uma literatura já bastante amadurecida que reflete sobre essa relação. Se uma delas reafirma a relação de conflito e oposição entre criminalidade e capacidades estatais, uma outra oferece uma interpretação alternativa a esse processo. Isso porque o Iraque não é um caso isolado. Estudiosos identificam uma tendência comum de que a criminalidade avance na medida em que as operações de reconstrução de Estados evoluem. Dentre as hipóteses levantadas pela literatura, destaca-se o fato de que os processos de paz podem produzir condições adequadas ao crescimento de mercados informais ou ilegais, já que estes também necessitam de estabilidade e previsibilidade para seus negócios. A própria máquina das operações de paz ou das ocupações estrangeiras, de maneira geral, produzem novos mercados legais e ilegais, como é o caso do mercado da prostituição. Por fim, os processos de reconstrução de Estados também são acompanhados de uma reformulação das normas e dos sistemas de justiça, o que resulta na criminalização e repressão sobre práticas até então não controladas pela autoridade estatal. Há, portanto, a possibilidade de uma relação de complementaridade entre criminalidade e intervenções internacionais. Tais possibilidades alternativas de interpretação são, sob nosso olhar, um convite a futuras pesquisas que abordem a temática da criminalidade no Iraque sob ocupação estadunidense de maneira crítica às narrativas dominantes construídas pelos próprios atores políticos.Para além da ampliação interpretativa do fenômeno da criminalidade e 
intervenções, entende-se, também, que é importante incentivar pesquisas empíricas quantitativas no intuito de ampliar os dados sociais e fontes documentais sobre a criminalidade no Iraque pós-Saddam.

\section{Referências Bibliográficas}

AL-SAADI, S. Z. (2004), "Iraq's Post War Economy: A Critical Review". MEES. v. XLVII, 14,5.

AMARAL, R. (2019), "The United States influence in Iraq's post-Saddam reconfiguration of power". Carta Internacional, 14,3: 168-191.

ANDREAS, P. (2011), "Illicit Globalization: Myths, Misconceptions, and Historical Lessons". Political Science Quarterly, 126, 3: 403-425.

ANDREAS, P.; NADELMANN, E. (2006), Policing the Globe: criminalization and crime control in international relations. Oxford: Oxford University Press.

AIA (2010), "Urges Protection of Iraq's Archaeological Heritage". Disponível em: $<$ https://www.archaeological.org/aia-urges-protection-of-iraqs-archaeologicalheritage/> consultado em 22/05/2021.

BERDAL, M.; MALONE, D.M. (2010), Greed and grievance: economic agendas in civil wars. Boulder: Lynne Rienner Publishers: 68-90.

BOWLING, B.; SHEPTYCKI, J. (2012), Global Policing. London: SAGE Publications Ltd.

CAP (2003), Document 220 FY04 Supplemental Request to Rehabilitate and Reconstruct Iraq 17 September 2003. Baghdad.

(2004), Coalition Provisional Authority: An Historic Review of CPA Accomplishments. Baghdad.

CHANDLER, D. (2004), The Responsibility to Protect? Imposing the 'Liberal Peace'. International Peacekeeping, 11,1:59-81.

CHITALKAR, P.; MALONE, D. (2013), The UN Security Council and Iraq. United Nations University Working Paper Series. n. 1, United Nations University.

COLLIER, P.; HOEFFLEY, A. (2004), "Greed and grievance in civil war". Oxford Economic Papers 56: 563-595.

DOBBINS et al. (2009), Occupying Iraq: a history of the coalition provisional authority. Santa Monica: RAND Corporation.

DODGE, T. (2013), "Intervention and dreams of exogenous statebuilding: The application of Liberal Peacebuilding in Afghanistan and Iraq". Review of International Studies, 39, 5: 1189-1212.

DUFFIELD, M. (2010), "Globalization, Transborder Trade, and War Economies". In: BERDAL, M.; MALONE, D.M. Greed and grievance: economic agendas in civil wars. Boulder: Lynne Rienner Publishers: 68-90.

EGAN, D. (2007), "Globalization and the invasion of Iraq: State power and the enforcement of neoliberalism". Sociological Focus, 40,1: 98-111. 
FASSIN, D. (2012), Humanitarian Reason: A moral history of the Present. Berkeley: University of California Press.

FAUCON, B; KANTCHEV, G. MACDONALD, A. (2017), "The Men Who Trade ISIS Loot: The middlemen who buy and sell antiquities looted by Islamic State from Syria and Iraq explain how the smuggling supply chain works". The Wall Street Journal. Disponível em: <https://www.wsj.com/articles/the-men-who-trade-isis-loot-1502017200>consultado em 22/05/2021.

FELBAB-BROWN, V. (2009), "Peacekeepers Among Poppies: Afghanistan, Illicit Economies and Intervention". International Peacekeeping, 16:1: 100-114.

FOX, G. (2008), Humanitarian Occupation. Cambridge: Cambridge University Press.

FUKUYAMA, F. (2006), Nation-building: Beyond Afghanistan and Iraq. Baltimore: The Johns Hopkins University Press.

GAO (2006), Rebuilding Iraq: Status of Funding and Reconstruction Efforts. US Government Accountability Office.

GAVIGAN, P. (2009), "Organized Crime, Illicit Power Structures and Guatemala's Threatened Peace Process". International Peacekeeping, 6, 1: 62-76.

GOLDSMITH, A.; SHEPTYCKI, J. (2007), Crafting Transnational Policing: Police Capacity-Building and Global Policing Reform. London: Bloomsbury Publishing.

HANSEN, W. (2014), "The Organized Crime - Peace Operations Nexus". PRISM, 5, 1:62-79.

HARRIS, G. (2006), The Era of Multilateral Occupation. Berkeley Journal of International Law, 24, 1: 1-78.

HERRING, E.; RANGWALA, G. (2006), Iraq in Fragments: The Occupation and its Legacy. Ithaca, New York: Cornell University Press.

. (2008), "Iraq, Imperialism and Global Governance". Third World Quarterly, $26: 4-5,667-683$.

.(2008), "Neoliberalism Versus Peacebuilding in Iraq". In: PUGH, M.; COOPER, N.; TURNER, M. Whose Peace? Critical Perspectives on the Political Economy of Peacebuilding. Hampshire; New York: Palgrave MacMillan.

JOHNSTON, P. et al (2019), "Return and Expand? The Finances and Prospects of the Islamic State After the Caliphate". RAND Corporation. Disponível emL $<$ https://www. rand.org/pubs/research_reports/RR3046.html> consultado em 2/05/2021.

KAN, P. R. (2007), "Drugging Babylon: The Illegal Narcotics Trade and Nation-Building in Iraq". Small Wars \& Insurgencies, 18, 2: 216-230.

KLEIN, N. (2008), The Shock Doctrine: The Rise of Disaster Capitalism. New York: Metropolitan Books.

KUHN, F., REUTER, C., TORABI, Y., ZOPPEI, V. (2013), "Afghanistan". In Heinrich-BöllStiftung \&Schönenberg R. (Eds.), Transnational Organized Crime: Analyses of a Global Challenge to Democracy: 77-114. 
LOONEY, R. (2006a), "Economic Consequences of Conflict: The Rise of Iraq's Informal Economy". Journal of Economic Issues. $x \mid, 4: 1-17$.

(2006b), "The Iraqi Impasse: Sustaining Economic Reconstruction During War-

Time". International Journal on World Peace. XXIII, 4: 3-31.

(2005), "Iraq's Shadow Economy". International Review of Economics and

Business, 4: 561-579.

MALONE, D.; CHITALKAR, P. (2013), The UN Security Council and Iraq. United Nations University Working Paper Series. United Nations University.

MCCALLISTER, A. (2005), "Organized Crime and the Theft of Iraqi Antiquities". Trends in Organized Crime. 9,1.

MCCULLOCH, J. (2007), "Transnational Crime as Productive Fiction". Social Justice, 34, 2: 19-32.

MERCILLE, J. (2013), Cruel Harvest: US Intervention in the Afghan Drug Trade. London: Pluto Press.

NADELMANN, N. (1993), Cops Across Borders: the Internationalization of U.S. Criminal Law Enforcement. Pennsylvania: Penn State Press.

NEWMAN, E.; PARIS, R.; RICHMOND, O. (2009), New Perspectives on Liberal Peacebuilding. New York: United Nations University Press.

OIL MINISTRY OF IRAQ (2006), Smuggling Crude Oil and Oil Products: Second Transparency Report. Disponível em <https://resourcegovernance.org/sites/ default/files/052206.pdf> consultado em 22/05/2021.

ONU. (2019), The nexus between international terrorism and organized crime. Joint special meeting of the Counter-Terrorism Committee, the Security Council. Friday, 26 Ap.

PARIS, R. (1997), Peacebuilding and the Limits of Liberal Internationalism. International Security, 22,2: 54-89.

(2004), At War's End: Building Peace After Civil Conflict. Cambridge: Cambridge University Press.

. (2010), Saving Liberal Peacebuilding. Review of International Studies, 36,2: 337-365.

PUREZA, J. M. (2018). O desafio crítico dos estudos para a paz. Organicom, 15, 28:74-89.

RATNER, S. (2005), Foreign Occupation and International Territorial Administration: The Challenges of Convergence. The European Journal of International Law 16,4: 695-719.

SHELLEY, L. (2020), "Illicit Trade and Terrorism". Perspectives on Terrorism, 14,4: 7-2.

STANFIEL, D. (2019), The Unintended Consequences of Upstreamin: Western Engagement on Iraq. In: CLARK, T.; JOHNSON, R. (Eds), Before Military Inter vention: Upstream Stabilisation in Theory and Practice. Switzerland: Palgrave Macmillan. 
TALMON, S. (2013), The Occupation of Iraq: The Official Documents of the Coalition Provisional Authority and the Iraqi Governing Council. Oxford: Hart Publishing.

UNODC (2003), Organized crime to be a growing problem in Iraq UNODC factfinding mission reports. Disponível em: $<$ http://www.unodc.org/unodc/press release_2003-08-27_1.html>, consultado em 22/05/2021.

USA (2009), "U.S. Embassy in Iraq". The SFA and U.S.-Iraqi Bilateral Relations. (2005), "International Narcotics Control Strategy Report (INCSR)". Bureau of International Narcotics and Law Enforcement Affairs (INL) 2005.

(2009), "International Narcotics Control Strategy Report (INCSR)". Bureau of International Narcotics and Law Enforcement Affairs (INL) 2009.

WAHAB, B. A. (2006), "How Iraqi Oil Smuggling Greases Violence". Middle East Quarterly: 53-59.

WILLIAMS, P. (2009), "Organized Crime and Corruption in Iraq". International Peacekeeping, 18, 1: 115-135

(2010), "Organized Crime in Iraq: Strategic Surprise and Lessons for Future Contingencies". PRISM, 1,2: 47-68. 


\section{Resumo}

\section{Compreensões sobre a ascensão da criminalidade e a reconstrução do Estado iraquiano: nexos de competição e complementaridade}

Em 2003 os EUA invadiram o Iraque e iniciaram um processo de reconstrução do Estado iraquiano. $O$ combate à criminalidade ganhou destaque, pois era visto como pressuposto e, também, um resultado do fortalecimento da autoridade estatal. A relação entre intervenções internacionais e criminalidade foi estudada por uma ampla literatura. Objetivamos sistematizar as interpretações levantadas sobre o caso iraquiano à luz do que foi desenvolvido por estudiosos dedicados a compreender a relação entre intervenções internacionais e criminalidade. Classificamos a literatura em dois grupos: um primeiro, que estabelece uma relação conflitiva e competitiva e outro, que identifica complementaridade entre criminalidade e processos de reconstrução de Estados. Com isso, buscamos oferecer novos trajetos interpretativos para futuras pesquisas sobre o Iraque.

Palavras-chave: Criminalidade; Reconstrução de Estados; Intervenção; Iraque; Estados Unidos.

\section{Abstract \\ Interpretations on the Rise of Crime and Statebuilding in Iraqi: links of Competition and Complementarity}

In 2003 the US invaded Iraq and began a process of rebuilding the Iraqi state. The crime control gained prominence, as it was seen as a presupposition and, at the same time, a result of the strengthening of state authority. The relationship between international interventions and crime has been studied by wide range of scholars. We aim to systematize the interpretations raised about the Iraqi case considering what has been developed by scholars dedicated to understanding the relationship between international interventions and criminality. We classify the literature into two groups: the first, which establishes a conflicting and competitive relationship, and the other, which identifies complementarity between criminality and statebuilding. From there, we seek to offer new interpretive paths for future research on Iraq.

Keywords: Crime; Statebuilding; Intervention; Iraq; United States.

\section{Resumé}

\section{Comprendre la montée de la criminalité et reconstruire l'État irakien: liens de concurrence et de complémentarité}

En 2003, les États-Unis ont envahi l'Irak et ont entamé un processus de reconstruction de l'État irakien. La lutte contre la criminalité a pris de l'importance, car elle était considérée comme un présupposé et aussi le résultat du renforcement de l'autorité de l'État. La relation entre les interventions internationales et la criminalité a été étudiée dans un grand numéro de rechercher. Nous visons à systématiser les interprétations soulevées à propos du cas irakien à la lumière de ce qui a été développé par des universitaires dédiés à la compréhension de la relation entre les interventions internationales et la criminalité. Nous avons classifié la littérature en deux groupes : le premier, qui établit une relation conflictuelle et concurrentielle, et l'autre, qui identifie une complémentarité entre la criminalité et les processus de reconstruction de l'État. Avec cela, nous cherchons à offrir de nouvelles pistes d'interprétation pour les recherches futures sur l'Irak.

Mots clés : Criminalité ; Renforcement de l'État ; Intervention ; Irak ; États Unis. 